\title{
Óleo de semente de tabaco: Otimização da extração por prensagem
}

\author{
José Otávio de Moura Leitão ${ }^{1}$ \\ Francieli Anneter Priebe ${ }^{2}$ \\ Francesca Fornasier $^{2}$ \\ Jonas Alvaro Kaercher ${ }^{3}$ \\ Rosana de Cassia de Souza Schneider ${ }^{4}$
}

\section{RESUMO}

O tabaco é principalmente usado para produzir cigarros e charutos, os quais são consumidos no mundo inteiro. No entanto, esse hábito não é benéfico para os usuários e a Organização Mundial da Saúde está buscando a redução deste uso para o tabaco. Nesse sentido, é necessário de outras destinações da planta tabaco que não seja somente para o setor fumageiro. Uma das alternativas do uso da cultura do tabaco é extrair o óleo de suas sementes para produção de biodiesel e outros bioprodutos. Com esse intuito, realizou-se um estudo para otimizar a extração na prensa de rosca ERT 60 (Scott Tech), comparando-se, por seguinte, duas luvas extratoras: a padrão e a otimizada, e dois tipos de sementes de tabaco: residual do Virgínia e a Solaris. Observou-se que com a utilização da luva otimizada houve aumento no rendimento de extração de 8,72\% para a semente residual Virgínia e de 11,49\% para a semente Solaris em relação à luva extratora padrão. Concluiu-se que o objetivo estabelecido de otimizar a extração por prensagem de óleo da semente de tabaco foi alcançado.

Palavras chaves: Tabaco. Extração. Óleo de semente. Biodiesel. Nicotiana tabacum.

\section{ABSTRACT}

Tobacco is mainly used to produce cigarettes and cigars, which are consumed worldwide. However, this habit is not beneficial to smokers and the World Health Organization is seeking to decrease its use. In this sense, it is need other destinations of the tobacco plant, which is not only for the cigarette sector. One of alternatives of using tobacco crops is to extract oil from its seed in order to produce biodiesel and others bioproducts. With this propose, a study was carried out to optimize the extraction on the screw press ERT 60 (Scott Tech), comparing two extraction's gloves: the standard and the optimized, and two types of tobacco seeds: residual of Virgínia and the Solaris. It was observed that with the use of optimized's gloves there was an increase in the extraction yield of $8.72 \%$ for the Virgínia's residual seed and of $11.49 \%$ for Solaris's seed in relation to the standard extraction's glove. It was concluded that the established objective of optimizing the extraction by oil pressing of the tobacco seed was achieved.

Keywords: Tobacco. Extraction. Seed oil extraction. Biodiesel. Nicotiana tabacum.

\footnotetext{
${ }^{1}$ Aluno do Curso de Engenharia Mecânica da Universidade de Santa Cruz do Sul - UNISC.

${ }^{2}$ Aluno do Curso de Química da Universidade de Santa Cruz do Sul.

${ }^{3}$ Professor do Departamento de Engenharia, Arquitetura e Ciências Agrarias d a Universidade de Santa Cruz do Sul.

${ }^{4}$ Professora do Departamento de Química e Física e do Programa de Pós-Graduação em Tecnologia Ambiental na Universidade de Santa Cruz do Sul. > rosana@unisc.br>
} 


\section{INTRODUÇÃO}

O tabaco é uma das maiores culturas não alimentícias do mundo e está presente em mais de 100 países (ATABANI et al., 2013). No entanto, seu cultivo é principalmente voltado para gerar folhas para a fabricação de cigarros e charutos, sendo esse mundialmente comercializado para fumar, algo que é extremamente danoso à saúde do ser humano (GIANNELOS et al., 2002; EZZELDIN et al., 2017; GARCÍA-MARTÍNEZ et al., 2017). Devido aos problemas causados pelo tabagismo, a OMS criou a Convenção-Quadro para o Controle do Tabaco (CQCT) cujo objetivo é proteger as gerações do presente e do futuro contra os efeitos nocivos causados pela fumaça do tabaco (WHO-FCTC, 2014). Sendo que através da CQCT estabeleceu-se a necessidade da diversificação do uso do tabaco, assim proporcionando outras finalidades ao cultivo não sendo só para o setor cigarreiro (CHIRIRIWA et al., 2014).

O tabaco (Nicotiana tabacum L.) é uma planta que quando desenvolvida possui de 90 a $180 \mathrm{~cm}$ de altura, além das folhas grandes, utilizadas para a produção cigarreira, existe também as flores que possuem coloração rosa e capsulas verdes que guardam as sementes da planta (USTA, 2005; USTA et al., 2011). Essa planta pode ser cultivada em diferentes zonas climáticas e tipos de solo, devido a sua robustez (FOGHER et al., 2011).

Existem mais de 80 espécies de tabaco, uma delas é o Nicotiana tabacum. Um dos tipos de $N$. tabacum é o Virginia, que é usualmente utilizado pelas cigarreiras para manufaturar o cigarro (FOGHER et al., 2011; OLIVEIRA; COSTA, 2012).

Outro tipo é o Solaris que foi especialmente desenvolvido pela empresa Sunchem (patente internacional PCT/IB/2007/053412) para se extrair óleo e, comparado com o tabaco usual, empregado para fabricação de cigarros não contém nicotina em suas folhas, produz mais sementes e pode ter até três colheitas no ano (FOGHER, 2008; FOGHER et al., 2011).

A semente de tabaco não possui nicotina o que a difere da folha que se usa no cigarro. Segundo Patel (1998) esta semente tem valor nutricional melhor do que a semente de amendoim e de algodão e é similar a semente de cártamo. Além disso, ela pode ser conservada por longos períodos se for estocada seca, também sendo resistente a altos níveis de umidade em temperaturas regulares e possui uma casca muito resistente (GIANNELOS et al., 2002). O teor de óleo existente em suas sementes é entre 30\% a 43\% do seu peso, contendo principalmente os ácidos graxos linoleico 65 a 75\%, oleico 10 a 16\%, palmítico 8 a 11\%, e esteárico 2 a 3\% (CHU; Tso, 
1968; GIANNELOS ET al., 2002; MUKHTAR et al., 2006; STANISAVLJEVIĆ et al., 2007; FOGHER et al., 2011; KUMAR; SHARMA, 2015; SHARMA et al., 2015).

O plantio do tabaco consiste na produção de mudas, cultivo na lavoura e colheita (Oliveira; Costa, 2012). A primeira fase necessita de empresas que produzam sementes de tabaco de qualidade, que germinem e virem mudas, e a segunda é executada por agricultores. Entretanto, na produção de sementes com o intuito de obter alta taxa de germinação, há uma seleção pela indústria, gerando sementes residuais, as quais, não germinam, mas tem alta qualidade para a produção de óleo, podendo receber um destino nobre (CHIRIRIWA et al., 2014).

A partir do óleo de tabaco é possível gerar lubrificantes, sabão, tintas e bioprodutos que podem ser aplicados tanto na medicina como na farmacologia. No entanto, em função de suas propriedades físico-químicas tem sido investigado para produzir biodiesel e outros biocombustíveis (USTA, 2005; STANISAVLJEVIĆ et al., 2007; USTA et al., 2011; CHIRIRIWA et al., 2014). As vantagens do uso do óleo desta cultura para biocombustíveis estão relacionadas ao alto teor de óleo que a semente possui, ao fato do óleo não ser utilizado para a alimentação humana e por esta cultura agrícola já estar consolidada no mundo inteiro (GIANNELOs et al., 2002, MUKHTAR et al., 2006, STANISAVLJEVIć et al., 2007).

No entanto para usar este óleo para biocombustíveis, o método de extração ainda deve ser explorado, uma vez que a semente é muito pequena e as condições de processo precisam ser melhoradas.

O óleo pode ser extraído por três métodos principais: (i) extração mecânica, (ii) extração por solvente e (iii) extração por enzimas, sendo que cada peculiaridade de extração está conforme Tabela 1.

A extração de óleo por meio de prensa mecânica é largamente utilizada em extrações com sementes na indústria (FAUGNO et al., 2016). E há dois tipos de prensas mecânicas: (i) com cilindro e (ii) de rosca. A primeira funciona através do movimento alternativo de um cilindro hidráulico que espreme as sementes, sendo aplicada em uso doméstico, rural e em casos que não necessitem grande volume de óleo. Já o segundo tipo pode ser dividido em prensa mecânica de rosca com luva extratora e de orifício no cilindro. Essas tem utilidade quando se requer uma demanda maior de óleo e um processo contínuo, porém precisa-se de mais sementes para que isso ocorra (SIREGAR et al., 2015). 
Tabela 1 - Tipos de extração de óleo

\begin{tabular}{|c|c|c|c|}
\hline Tipos de extração & Vantagens & Desvantagens & Rendimento de óleo (\%) \\
\hline Mecânica & $\begin{array}{l}\text { - Fácil utilização; } \\
\text { - Não necessita solvente; } \\
\text { - Baixa manutenção; } \\
\text { - Extrai óleo sem } \\
\text { necessitar retirar a semente } \\
\text { do fruto; }\end{array}$ & $\begin{array}{l}\text { - Necessita grandes quantidades de } \\
\text { material; } \\
\text { - Requer processo de filtração } \\
\text { posterior; } \\
\text { - Design e configuração da máquina } \\
\text { específica para cada tipo de } \\
\text { semente; }\end{array}$ & $60-87$ \\
\hline Solvente & $\begin{array}{l}\text { - Solventes usados são } \\
\text { relativamente baratos e } \\
\text { podem ser reciclados; }\end{array}$ & $\begin{array}{l}\text { - Necessita-se grande quantidade de } \\
\text { solvente que são inflamáveis e } \\
\text { tóxicos; } \\
\text { - Viável economicamente somente } \\
\text { em larga escala }\end{array}$ & $60-99$ \\
\hline Enzimática & $\begin{array}{l}\text { - Não agride o meio } \\
\text { ambiente; } \\
\text { - Não produz componentes } \\
\text { orgânicos voláteis; }\end{array}$ & $\begin{array}{l}\text { - Necessita que as sementes estejam } \\
\text { trituradas; }\end{array}$ & $38-86$ \\
\hline
\end{tabular}

Fonte: Adaptado de (STANISAVLJEVIĆ et al., 2007; ATABANI et al., 2013; KUMAR; SHARMA, 2015;

SIREGAR et al., 2015; AHMAD et al., 2016)

Em virtude disso e do atual contexto energético mundial que torna necessário desenvolver processos mais sustentáveis e assim realizar estudos em escala piloto, efetuou-se um estudo para otimizar o processo de extração do óleo da semente de tabaco por prensagem em um equipamento que permite extrair o óleo em escala piloto. Para o estudo utilizaram-se dois tipos de semente: residual do tabaco Virgínia e sementes colhidas de uma lavoura experimental de tabaco Solaris.

\section{MATERIAIS E MÉTODOS}

O experimento contemplou a extração por prensagem dos óleos das sementes de tabaco Virgínia e Solaris. Utilizaram-se duas luvas extratoras do fabricante Scott Tech, uma delas padrão, e a outra desenvolvida pela fornecedora para extração de semente de tabaco, conforme Figura 1. Através da comparação entre os dados obtidos com as duas luvas para os dois tipos de sementes de tabaco, obteve-se o acessório com melhores condições de trabalho com semente de tabaco.

\section{Figura 1 - Luvas extratoras: (A) uso geral e (B) otimizada}




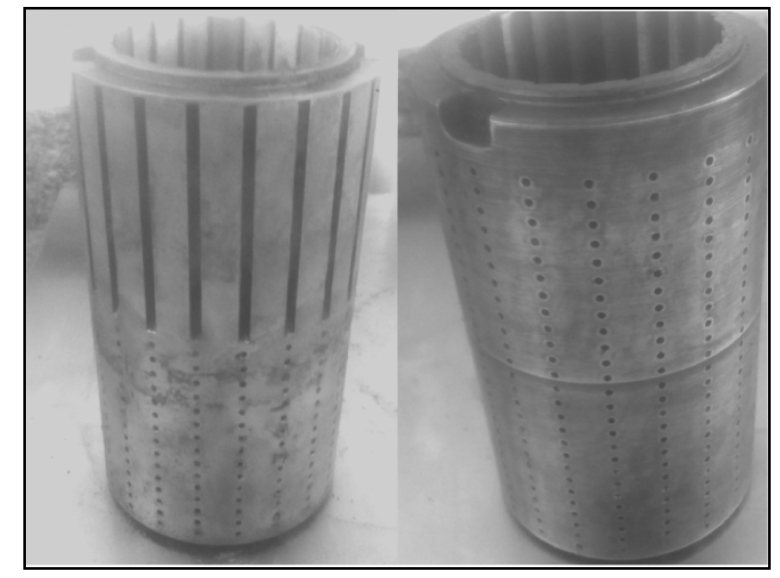

Fonte: elaborado pelos autores (2016).

O método utilizado consistiu de quatro bateladas de extração com frações de 20 kg para cada tipo de semente e de luva extratora. A primeira batelada no início de cada mudança não é considerada nos resultados finais, pelo fato de ter apenas o objetivo de homogeneizar o regime. Assim, resultou em uma quantia de $160 \mathrm{~kg}$ de sementes de cada tipo, totalizando $320 \mathrm{~kg}$ de sementes de tabaco.

A troca de luvas foi realizada sem ocorrer nenhuma alteração no resto do equipamento. Para cada vez que se alternam as sementes e as luvas, foi realizada uma limpeza na máquina para retirar impurezas que pudessem prejudicar os resultados. Avaliou-se, a partir da extração, o rendimento em óleo, quantidade de borra, quantidade de torta, perdas no processo, teor de óleo residual na torta. E o procedimento foi repetido para ambos os tipos de sementes.

Avaliou-se também o estado de conservação do óleo periodicamente com os testes de índice de acidez e de iodo, quando adicionado o antioxidante EnHance A123S (Kemin) com diferentes concentrações.

\subsection{Secagem}

A primeira etapa para extrair o óleo das sementes de tabaco foi utilizar o processo de secagem, visando aquecer e desumidificar as sementes. Dessa maneira deixando o óleo menos viscoso e aumentando o rendimento da extração. A temperatura estabelecida foi em torno de 90 ${ }^{\circ} \mathrm{C}$ e utilizou-se a Secadora Misturadora Rotativa SMG 610-G, do fabricante Scott Tech. Após a retirada das sementes quantificaram-se as massas delas, assim obtendo-se um valor preciso de entrada no processo de extração. 


\subsection{Extração}

Em seguida, as sementes foram inseridas na Extratora radial tubular ERT 60 (Scott Tech). Nesse equipamento há a extração do óleo pelo fenômeno da compressão que uma rosca escalona exerce sobre a luva extratora, que possui orifícios com a finalidade de separar o conjunto óleo/borra da torta. Esse evento ocasiona na geração de calor pelo atrito entre as sementes e também pelo contato delas com o equipamento, havendo um ajuste cônico no fim da rosca com o suporte da luva extratora que possibilita alterar a folga de saída de torta, e assim, os parâmetros de produção de óleo. Conforme a regulagem se terá diferentes formações de torta e geração de óleo.

\subsection{Filtração e centrifugação}

Como o óleo continha borra, em seguida, foi filtrado para separação do conjunto óleo/borra em uma peneira elástica de fios poliméricos. Pelo fato da filtração retirar as partículas até uma determinada granulometria, torna-se necessário remover o resto dos particulados e sedimentos com a utilização do processo de centrifugação. Dessa maneira utilizou-se a centrifuga de bancada SIGMA 6-16KS de capacidade de $1600 \mathrm{~mL}$ por batelada. Posteriormente, filtrou-se novamente o óleo no mesmo tipo de peneira elástica já utilizada anteriormente.

\subsection{Uso de antioxidante}

O uso de antioxidante foi testado com diferentes concentrações do mesmo. O antioxidante testado foi o EnHance A123S (Kemin).

Para este teste de adição de antioxidante, de $100 \mathrm{~kg}$ de semente foi extraído $30 \mathrm{~kg}$ de óleo de tabaco e $69 \mathrm{~kg}$ de torta. Após centrifugação foi obtido 20,25 L de óleo limpo sem borra com índice de refração de 1,4774. Neste óleo foi adicionado em mesmos volumes, concentrações diferentes de antioxidante. Periodicamente foi analisado o índice de acidez e de iodo segundo os métodos da American Oil Chemist’s Society (AOCS) para monitorar a qualidade do óleo. 


\section{RESULTADOS E DISCUSSÃO}

Os primeiros testes de extração de óleo realizados com a luva extratora padrão do equipamento de extração demonstrou que as perdas de semente não extraída ocorreram em função do design da luva extratora, como mostra a Figura 2. Constatou-se que com esta luva há necessidade de realizar o preenchimento das ranhuras para que se reduzam as perdas, e o óleo seja extraído principalmente nos orifícios finais. Para melhoria de rendimento também se constatou a necessidade de experimentar uma luva com design modificado, apta a extrair sementes pequenas, como as do tabaco.

\section{Figura 2- Registro fotográfico da etapa de extração, no início da prensagem}

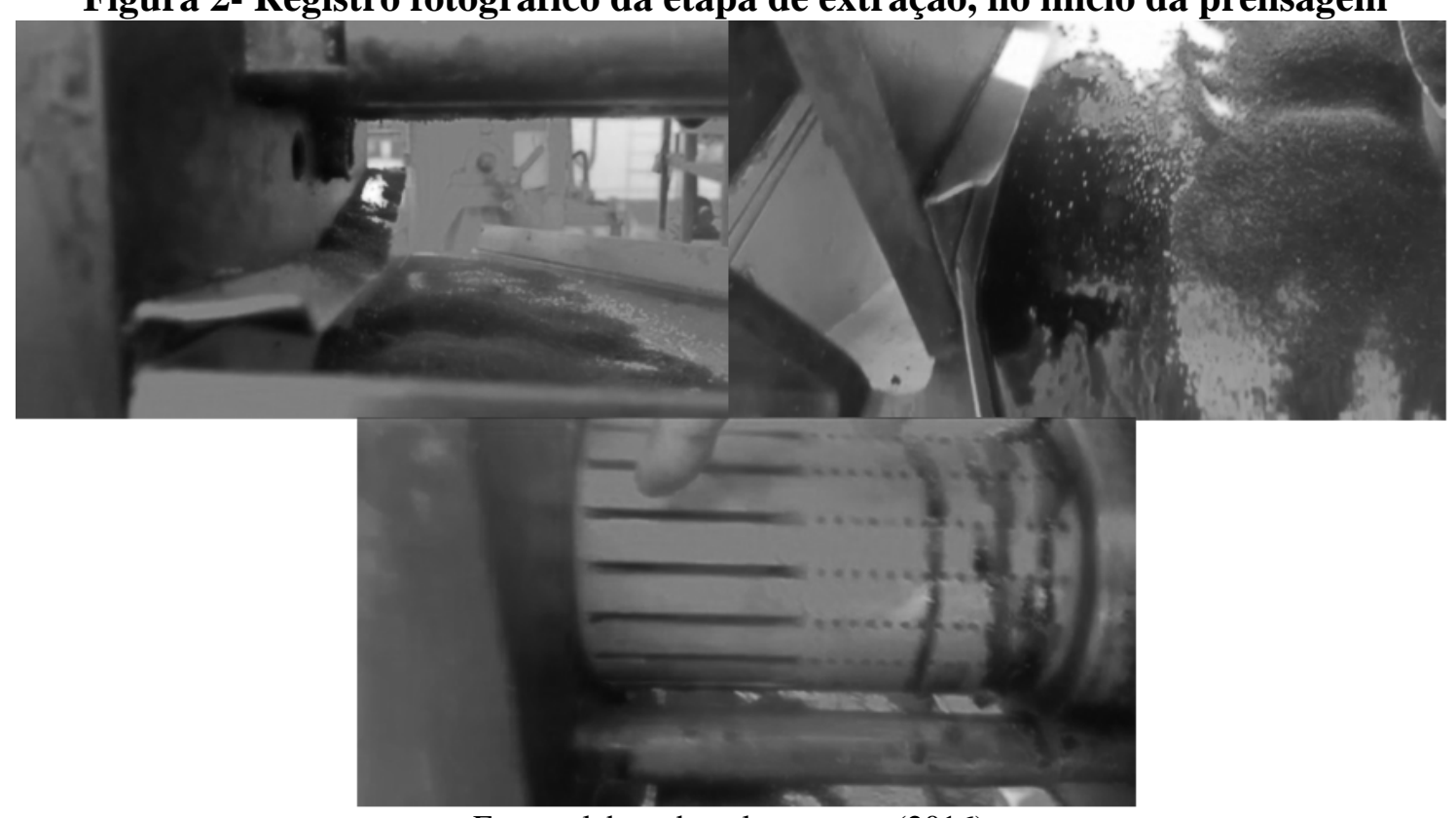

Fonte: elaborado pelos autores (2016).

Destaca-se que as sementes de tabaco são tão pequenas que se considerarmos um grama deste material, teremos em torno de 16 mil sementes (CALDEIRA et al., 2016). O que exige realmente uma modificação no processo de extração.

Assim, avaliamos os dois tipos de luva com relação ao rendimento em extração e as perdas, principalmente na forma de borra. 


\subsection{Adição de antioxidante no óleo}

Na Tabela 1, estão apresentados os resultados das análises do índice de iodo e de acidez do óleo após 1 semana e após 1 mês, com relação a quantidade de uso de antioxidante. Este teste foi realizado para determinar a concentração de antioxidante que seria adicionado no óleo para manter a qualidade por maior tempo.

Observou-se que mesmo com o uso de diferentes proporções de antioxidante, o óleo de tabaco se altera com relação ao índice de iodo e de acidez, no entanto, com o antioxidante podemos retardar o processo e armazenar o óleo para a produção de biodiesel. Este é um aspecto que deve ser levado em consideração para a produção de biodiesel. Considerou-se que 200 ppm de antioxidante pode ser adequado para manter a estabilidade do óleo no tempo necessário de armazenamento.

Tabela 1- Resultado das análises do óleo com adição de antioxidante.

\begin{tabular}{lllll}
\hline & \multicolumn{2}{c}{ Índice de Iodo $\mathbf{( \mathbf { m g I } _ { 2 } / \mathbf { g } )}$} & \multicolumn{2}{c}{ Índice de acidez(mg KOH/g) } \\
Início - 172,16 (II) ; 4,1 (IA) & 1 semana & 1 mês & 1 semana & 1 mês \\
200 ppm de antioxidante & 152,84 & 153,82 & 4,37 & 5,76 \\
500 ppm de antioxidante & 152,96 & 153,98 & 4,62 & 5,92 \\
1000 ppm de antioxidante & 153,04 & 153,77 & 5,08 & 5,69 \\
1200 ppm de antioxidante & 153,43 & 154,54 & 5,11 & 5,30 \\
\hline
\end{tabular}

Fonte: elaborado pelos autores (2016).

Assim, constatou-se que o antioxidante empregado, o qual normalmente é empregado para biodiesel, pode ser adicionado antes da transesterificação e retardar ou inibir a oxidação das insaturações. Além deste produto, outros antioxidantes podem ser utilizados com excelente resultado nesta etapa (BORSATO et al., 2010) e poderão permitir armazenagem do óleo por mais tempo.

\subsection{Otimização da extração}

Com a troca de luva foi observado um menor volume de borra. Na avaliação inicial, já se observa uma melhoria na extração. Com a luva otimizada, temos orifícios menores e conseguimos uma extração mais eficiente. Com este cilindro foi possível um melhor ajuste de alimentação da prensa e não houve a passagem de semente não extraída com o óleo, no entanto, a borra produzida ficou mais fina, e mais difícil de separar. 


\subsubsection{Semente Solaris}

Os dados das extrações com as duas luvas para a semente de tabaco Solaris são mostrados na Figura 3.

Através das informações da Figura 3 pode-se determinar o quanto variou de uma luva para outra e comparar os rendimentos delas, e isso é demonstrado na Figura 4.

A partir da Figura 4 é possível concluir que comparada à luva padrão, a luva otimizada aumentou 11,49\% na extração de óleo da semente Solaris. Além de diminuir a quantidade de torta, borra e o teor de óleo na torta. No entanto, houve maior volume de perdas o que está relacionado com a configuração mecânica da luva, a qual retém mais material no interior da rosca de compressão.

Figura 3 - Composição média das extrações de semente Solaris

Semente Solaris - Luva padrão

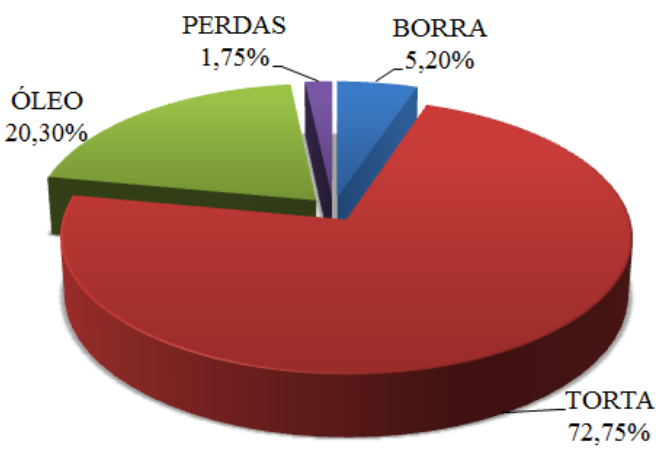

Semente Solaris - Luva otimizada

Teor de óleo na Torta
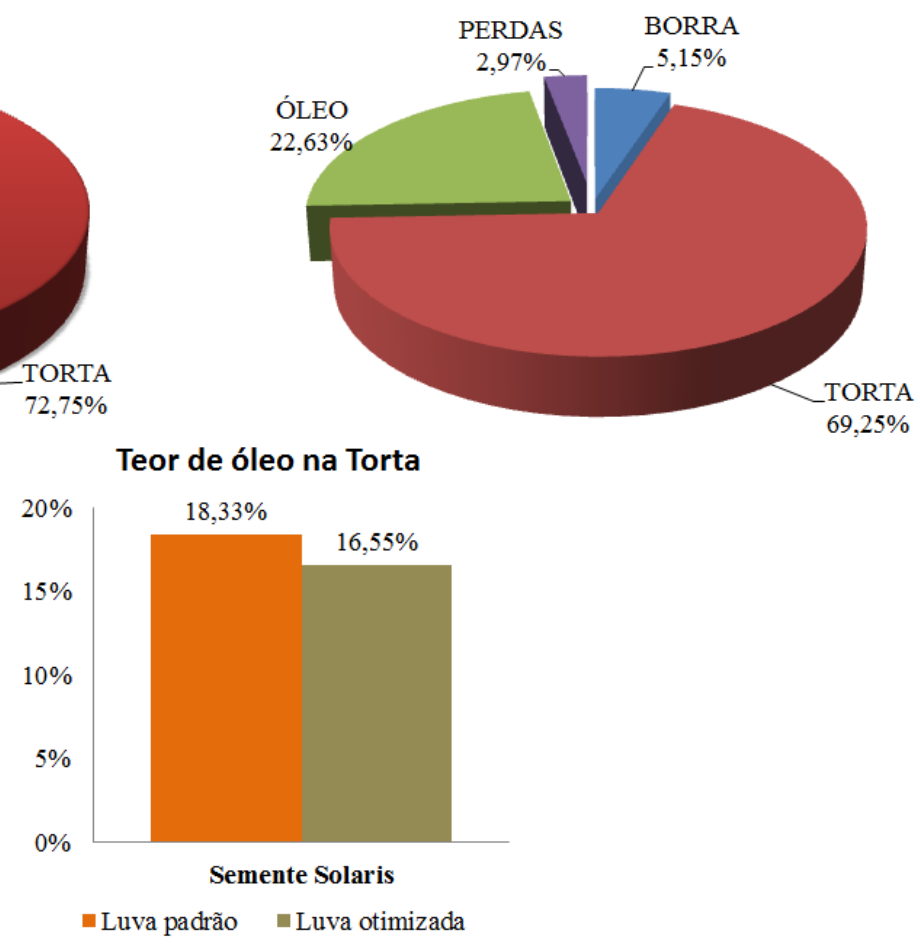

Fonte: elaborado pelos autores (2016). 


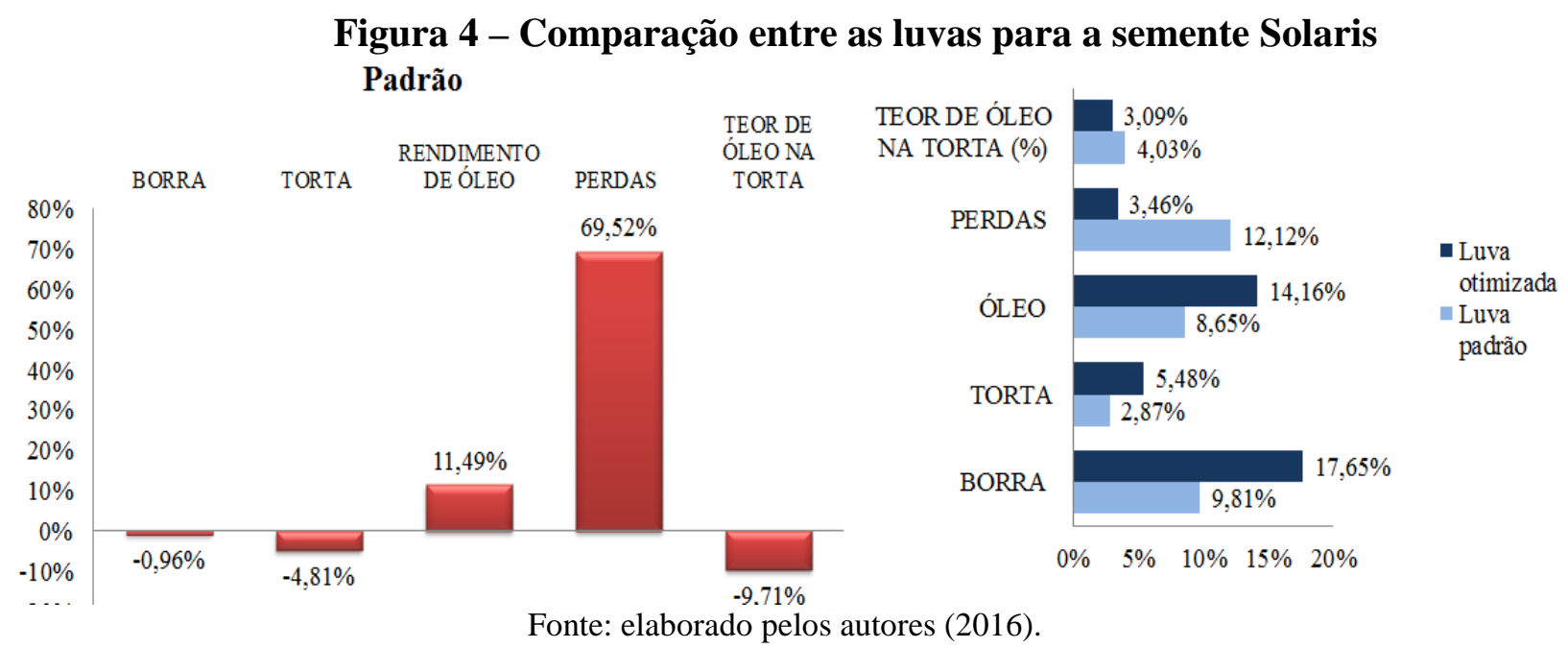

A variabilidade do processo com a luva otimizada se mostrou maior, porque as sementes Solaris utilizadas possuíam grande quantidade de impurezas (palhas, folhas e partes da flor) o que causava um entupimento momentâneo nos orifícios da luva e, desta maneira, fazendo com que oscilasse o processo.

\subsubsection{Semente residual Virgínia}

Os dados das extrações com as duas luvas para a semente de tabaco residual Virgínia são demonstrados na Figura 5.

Figura 5 - Composição média das extrações de semente residual Virgínia

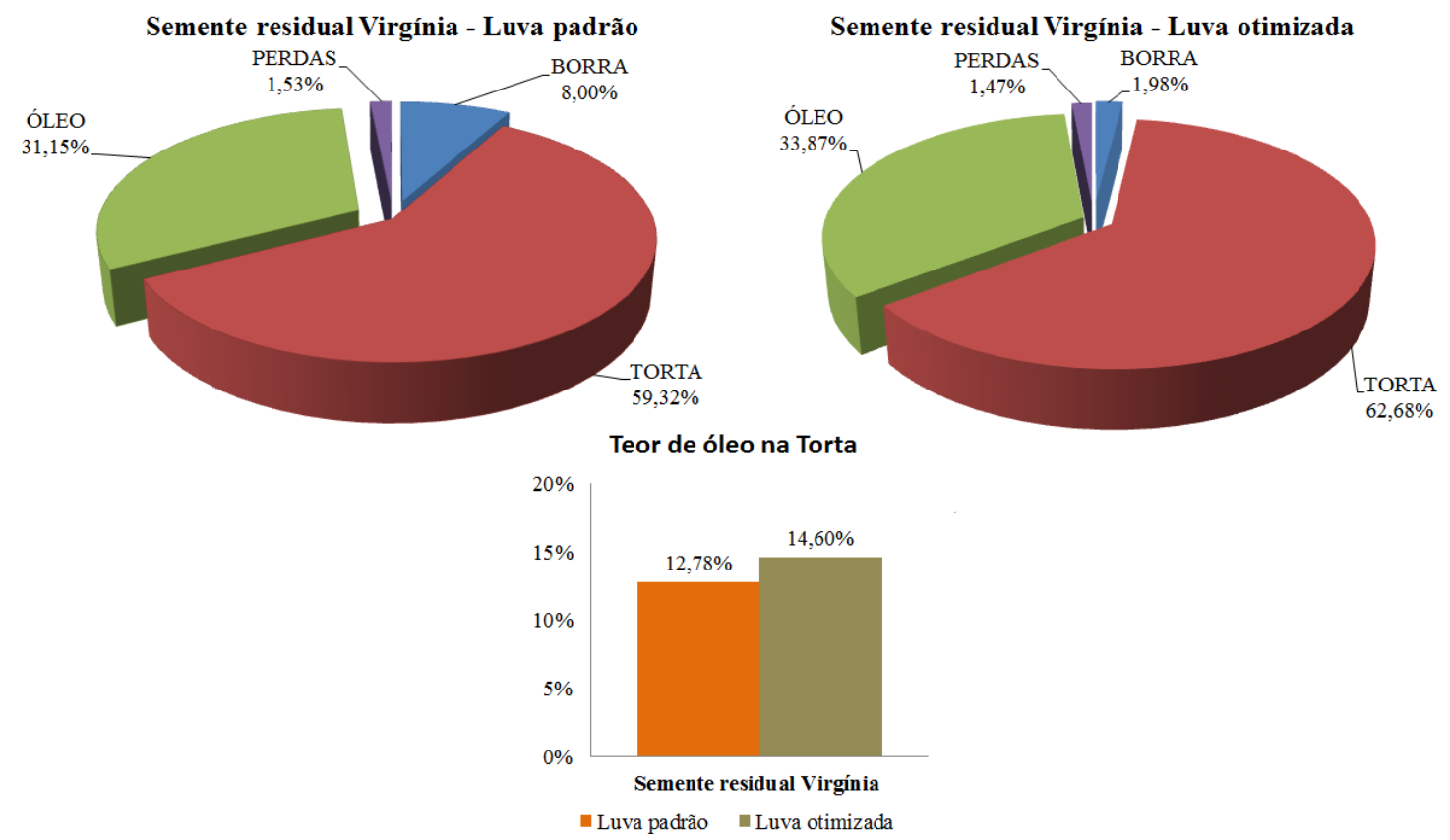

Fonte: elaborado pelos autores (2016). 
Com os dados da Figura 5 conseguiu-se comparar os valores entre as duas luvas, o que é mostrado na Figura 6.

Com os valores da Figura 6, conclui-se que em comparação aos rendimentos da luva padrão, a luva otimizada aumentou em 8,72\% no rendimento do óleo de semente residual Virgínia, além de diminuir o volume de borra e as perdas no processo. Entretanto, houve maior quantidade de torta e teor de óleo nela.

A variabilidade do processo com a luva otimizada se mostrou menor, pois as sementes residuais Virgínia utilizadas são homogêneas em forma e tamanho, e também não possuem quantidade de impureza que altere os rendimentos de extração.

Figura 6 - Comparação entre as luvas para a semente residual Virgínia

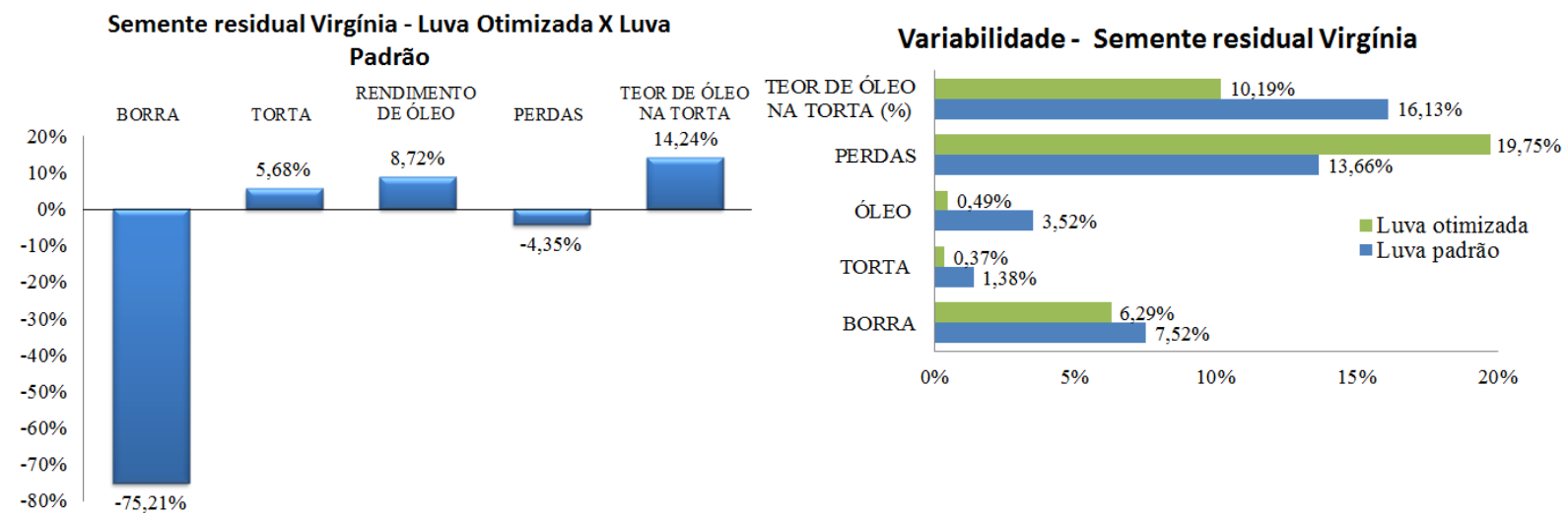

Fonte: elaborado pelos autores (2016).

\section{CONCLUSÃO}

A conclusão sobre a otimização do processo de extração de óleo de semente de tabaco por prensagem é de que tanto o com a semente de tabaco Solaris como o com a residual do Virgínia maiores rendimentos podem ser obtidos com a luva extratora otimizada, a qual apresenta orifícios compatíveis com o tamanho da semente e não possui rasgos axiais como na luva padrão, comumente empregada para a maioria das sementes oleaginosas. As perdas nos experimentos são decorrentes da desidratação durante o aquecimento inicial e perdas de transferência de material no processo de extração. 
Com a semente Virgínia, residual de processo industrial, obteve-se menor variabilidade no processo, pelo fato de ter menor concentração de impurezas como: palha, folhas e partes da flor em comparação com as amostras da semente Solaris obtidas em lavoura experimental.

O teor de óleo extraído da semente Virgínia por prensagem nas condições estudadas foi de 33,87\% e para o Tabaco Solaris foi de 22,63\%. Considerando que o valor esperado é de 33 à $40 \%$ de óleo do seu peso total, sugere-se que a diferença seja devido a limpeza das sementes, pois a semente Virgínia tem um processo de limpeza e seleção mais eficiente. A semente Solaris também poderá no futuro ser tratada em um processo industrializado e assim, levar a um melhor rendimento. Os resultados obtidos até este momento são promissores para a produção de óleo de semente de tabaco.

\section{REFERÊNCIAS}

AHMAD, K. A. et al. Extraction techniques and industrial applications of jatropha curcas. Jurnal Teknologi. Malaysia. v. 78, n. 7-3, p. 53-60, 2016. Acesso em 20 jan. 2017. DOI: 10.11113/jt.v78.9483

ATABANI, A. E. et al. Non-edible vegetable oils: A critical evaluation of oil extraction, fatty acid compositions, biodiesel production, characteristics, engine performance and emissions production. Renewable and Sustainable Energy Reviews v. 18, p. 211-245, 2013. Acesso em 18 dez. 2016. DOI: 10.1016/j.rser.2012.10.013

BORSATO, D. et al. Aplicação do delineamento simplex-centroide no estudo da cinética da oxidação de Biodiesel B100 em mistura com antioxidantes sintéticos. Química Nova. São Paulo. v. 33, n. 8, p. 1726-1731, 2010. Disponível em <http://quimicanova.sbq.org.br/imagebank/pdf/Vol33No8_1629_19-AR10051.pdf>. Acesso em 01 jan. 2017.

CALDEIRA, C. M. et al. Qualidade de sementes de tabaco durante o processo de pelotização e armazenamento. Ciência Rural. Santa Maria. v. 46, n. 2, p. 216-220, 2016. Acesso em 07 jan. 2017. DOI: $10.1590 / 0103-8478 c r 20141272$

CHIRIRIWA, H. et al. Tobacco seed oil as an economically viable alternative for the tobacco industry. International Conference of Chemical Engineering \& Advanced Computational Technologies. Pretoria. South Africa, p. 36-39, 2014. Acesso em 17 jan. 2017. DOI: 10. 15242/IIE.E1114017

CHU, H.; TSO, T. C. Fatty Acid Composition in Tobacco I. Green Tobacco Plants. Plant Physiology. v. 43, n. 3, p.428-433, 1968. Acesso em 02 jan. 2017. DOI: 10.1104/pp.43.3.428 
EZZELDIN, N. et al. Genetic polymorphisms of human cytochrome P450 CYP1A1 in an Egyptian population and tobacco-induced lung cancer. Genes and Environment. v. 39, n. 7, 2017. Acesso em 09 dez. 2016. DOI: 10.1186/s41021-016-0066-4

FAUGNO, S. et al. Mechanical oil extraction of Nicotiana tabacum L. Seeds: Analysis of main extraction parameters on oil yield. Journal of Agricultural Engineering. Itália. v .47, n. 3, p. 142147, 2016. Acesso em 01 jan. 2017. DOI: 10.4081/jae.2016.539

FOGHER, C. Mutagenized tobacco plant as seed culture for production of oil for energetic, industrial and alimentary uses. WO2008110876 A1. 18 set. 2008

FOGHER, C. et al. Developing tobacco's potential as a novel, high-yielding, renewable energy plant. International News on Fats, Oils and Related Materials v. 22, n. 10, p. 631-634, 2011. Disponível em: $<$ http://www.sunchem.it/wp-content/uploads/2012/07/INFORM_novDec_2011.pdf>. Acesso em 03 dez. 2016.

GARCÍA-MARTÍNEZ, N. et al. Optimization of non-catalytic transesterification of tobacco (Nicotiana tabacum) seed oil using supercritical methanol to biodiesel production. Energy Conversion and Management v. 131, p. 99-108, 2017. Acesso em 08 dez. 2016. DOI: 10.1016/j.fuel.2017.05.019

GIANNELOS, P. N. et al. Tobacco seed oil as an alternative diesel fuel: Physical and chemical properties. Industrial Crops and Products v. 16, n. 1, p. 1-9, 2002. Acesso em 04 jan. 2017. DOI: 10.1016/S0926-6690(02)00002-X

KUMAR, M.; SHARMA, M. P. Assessment of potential of oils for biodiesel production. Renewable and Sustainable Energy Reviews v. 44, p. 814-823, 2015. Acesso em 20 set. 2016. DOI: 10.1016/j.rser.2015.01.013

MUKHTAR, A. et al. Extraction and characterization of tobacco seed oil. Asian Journal of Chemistry v. 18, n. 1, p. 20-24, $2006 . \quad$ Disponível: <http://www.asianjournalofchemistry.co.in/User/ViewFreeArticle.aspx?ArticleID=18_1_4>.

Acesso em 15 dez. 2016

UNIVERSIDADE DE SÃO PAULO. Dossiê técnico: Cultivo de fumo (Nicotiana tabacum L.).São Paulo, 2012

PATEL, J. A. Production potential and quality aspects of tobacco seed oil. Patel, B. K., Tobacco Research. v. 24, p. 44-46, 1998.

SHARMA, K. et al. Biodiesel Production from Tobacco $<\mathrm{i}>($ Nicotiana Tabacum $)</ \mathrm{i}>$ Seed Oil. Journal of Earth, Environment and Health Sciences v. 1, n. 2, p. 61-65, 2015. Acesso em 01 dez. 2017. DOI: $10.4103 / 2423-7752.170588$

SIREGAR, A. N. et al. Comparison of oil press for jatropha oil - A review. Research in Agricultural Engineering v. 61, n. 1, p. 1-13, 2015. Acesso em 20 nov. 2017. DOI: 10.17221/22/2013-RAE 
STANISAVLJEVIĆ, I., et al., The extraction of oil from tobacco (Nicotiana tabacum L.) seeds. Chemical Industry and Chemical Engineering Quarterly v. 13, n. 1, p. 41-50, 2007. Acesso em 2 nov. 2017. DOI: 10.2298/CICEQ0701041S

USTA, N. Use of tobacco seed oil methyl ester in a turbocharged indirect injection diesel engine. Biomass and Bioenergy v. 28, n. 1, p. 77-86, 2005. Acesso em 3 jan. 2017. DOI: 10.1016/j.biombioe.2004.06.004

USTA, N. et al. Properties and quality verification of biodiesel produced from tobacco seed oil. Energy Conversion and Management v. 52, n. 5, p. 2031-2039, 2011. Acesso em 8 out. 2016. DOI: 10.1016/j.enconman.2010.12.021

WHO-FCTC. Verbatim records of plenary meetings. $6^{\circ}$ Conference of Parties to the WHO framework Convention on Tobacco Control, Moscow. 2014 